\title{
FIBER ORIENTATION AND FILLERS EFFECTS ON SPECIFIC HEAT OF FABRIC REINFORCED HYBRID EPOXY COMPOSITES
}

\author{
Marina BUNEA, Mihaela Claudia GOROVEI, \\ Claudia Veronica UNGUREANU, Vasile BRIA \\ "Dunarea de Jos" University of Galati, Romania \\ e-mail: marina.bunea@ugal.ro
}

\begin{abstract}
In this investigation, the specific heat of four fabric reinforced hybrid composite materials with filled stratified epoxy matrix was analysed. All hybrid composite materials were made of 17 layers, for which were used carbon, aramid, glass and hybrid fabrics. The stratified filled epoxy matrix of fabric reinforced hybrid composites represents a matrix, in whose structure it was used three types of fillers mixtures between certain plies. The investigation of specific heat of hybrid composite materials was performed by using of Differential Scanning Calorimetry instrument. It was analysed the effects of fiber orientation at various angles on specific heat of fabric reinforced hybrid composites with filled stratified epoxy matrix and the influence of fillers mixtures on these thermal properties of epoxy matrix. Also, it was studied the specific heat of hybrid epoxy composites in dependence of carbon and aramid plies number in studied materials structure.
\end{abstract}

KEYWORDS: hybrid stratified composites; filled epoxy matrix; fiber orientation; specific heat

\section{Introduction}

The thermosetting composite materials reinforced with fibers or fabrics are widely used in many applications, which are carried out under conditions with high or low temperatures, or under conditions with temperature variations. So, the temperature increasing or decreasing leads to volume deformation of the composite materials, which affects the structural stability. Thus, the thermal investigations of the composite materials are important, because their mechanical performance depends on their thermal deformations [1].

The thermal behaviour of the fiber reinforced thermosetting composites can be carried out by the investigation of specific heat, thermal conductibility, coefficient of thermal linear expansion, etc. [2]. In case of composite materials reinforced with fibers, the polymeric matrix and the fibers exhibits different temperature fluctuations due to their different thermoelastic constants [3]. The epoxy systems are the thermosetting polymers most widely used as matrix for fiber reinforced composite materials, due to their thermal stability, chemical resistance, mechanical properties and high adherence to all fiber types and inorganic fillers [4].
Considering the thermal properties of the reinforcement and matrix of the composites structures, it can be predicted their thermal behaviour and their mechanical resistance under conditions with temperature variations. In order to increase the structural stability, for example, for different types of constructions, it can be used the hybrid composites reinforced with different types of fibers and with filled polymeric matrix. Through hybridization it can be obtained the composite materials with desired properties, considering the properties of each constituent component, their compatibility and the quality of the fiber-matrix and filler-matrix interfaces [5].

For this study it was made an experimental investigation of specific heat of the hybrid composite materials reinforced with plain fabrics and with stratified filled epoxy matrix, which were formed, actually, in order to obtain multifunctional advanced composite materials. The stratified filled epoxy matrix represents an epoxy matrix modified with three types of fillers mixtures used for certain layers of the laminates. In order to obtain the stratified epoxy matrix, it was used the fillers such as potatoes starch, carbon black, aramid powder, ferrite, carbon and glass whiskers. 
In ref. [6] it was established that the $10 \mathrm{wt} . \%$ of corn starch had no influence on thermal stability (specific heat and coefficient of thermal expansion) in the temperature range of $70-110{ }^{\circ} \mathrm{C}$. The thermal conductivity of the epoxy composites increases with the increasing of the carbon black content [7, 8]. The specific heat of the nano-ferrites epoxy composites increase with the increasing of the nano-ferrite content in the temperature range of $70-120^{\circ} \mathrm{C}$ [9], but by adding $50 \mathrm{wt}$. $\%$ of clay in epoxy matrix the values of specific heat in the temperature range of $90-150{ }^{\circ} \mathrm{C}$ decrease with the increase of ferrite content from 20 to 50 wt.\% [10]. The thermal conductibility through thickness of the composites reinforced with fibers can be improved, also, by addition of fillers in polymeric matrix such as graphene nanoplatelets [11-13], carbon nanotubes [14, 15], graphite [16], metallic nanoparticles as $\mathrm{TiO}_{2}$ nanoparticles [17], nickel particles [18], up to $2 \mathrm{wt} . \%$ of $\mathrm{ZnO}$ nanoparticles [19] and another filler types. For example, in ref. [20] it was found that the thermal conductivity through thickness without affecting the mechanical resistance of carbon fiber reinforced composite laminates increased with $40 \%$ by addition of graphene nanoplatelets (1 vol.\%) together with silver nanoparticles and nanowires $(0.5 \mathrm{vol} . \%)$.

In this paper the influence of the fillers on specific heat of the epoxy matrix, fiber orientation and aramid/carbon plies number on specific heat of the hybrid composite materials was investigated.

\section{Materials and experimental method}

\subsection{Materials}

As epoxy matrix of fabric reinforced hybrid composites with stratified filled matrix, it was selected EPIPHEN 4020 system (DE resin and RE hardener) with 100:30 ratio, due to its properties before and after polymerization. After 14 days the complete polymerization is reached at laboratory conditions (temperature of $23{ }^{\circ} \mathrm{C}$ and humidity of $50 \%$ ). This used epoxy system exhibits a high adherence to all fiber types and to the most filler types.

As reinforcements for hybrid stratified composites it was used five plain fabric types: carbon fabric with $160 \mathrm{~g} / \mathrm{m}^{2}$ density, denoted C; aramid fiber fabric with $173 \mathrm{~g} / \mathrm{m}^{2}$ specific density, denoted A; glass fiber fabric with $163 \mathrm{~g} / \mathrm{m}^{2}$ specific density, denoted $1 \mathrm{G}$; glass fiber fabric with $390 \mathrm{~g} / \mathrm{m}^{2}$ specific density, denoted 2G; hybrid fabric with $270 \mathrm{~g} / \mathrm{m}^{2}$ specific density, denoted $\mathrm{M}$.

In order to obtain the hybrid fabric $M$, it was used a carbon aramid fiber mixed fabric with 205 $\mathrm{g} / \mathrm{m}^{2}$ specific density, whose weave geometry represents an alternated carbon fiber by two aramid fibers in the weft direction and alternated aramid fiber by two carbon fibers in the warp direction. Each second aramid fiber in the weft direction of mixed fabric was replaced by a tin covered copper wire with diameter of $0.2 \mathrm{~mm}$ and a glass fiber with linear density of 200 tex [21-23].

In order to improve the quality of matrix-fiber interface of fabric reinforced hybrid epoxy plates, which depends on the adherence properties of the fibers, all used fabrics were treated with detergent, sodium hydroxide and perchloric acid solutions by uniform spaying and they were cleaned after each treatment with water. After that the fabrics were dried and they were covered by uniform spraying with a thin film made of nitro diluent and used EPIPHEN epoxy system mixture.

The fillers such as aramid powder, carbon black, potatoes starch, barium ferrite and carbon and glass whiskers were selected in order to obtain the stratified epoxy matrix of multifunctional hybrid composite plates. The potatoes starch was mixed with another types of fillers due to experimental results obtained in ref. [24], which showed that the 10 wt.\% of corn starch can be used without affecting the electrical, thermal and mechanical properties of the epoxy composites, but it lead to an increase of the prepolymeric liquid viscosity by its swelling. So, it was ensured the uniform distribution of other selected fillers into prepolymeric mixtures and it was avoided their sedimentation. The carbon black and barium ferrite were used to improve the thermal and electromagnetic properties. In order to improve the mechanical properties and impact performance, it was used the aramid powder, carbon whiskers and glass whiskers.

It was formed four hybrid composites made of 17 layers, which were denoted in this paper $\mathrm{H} 1, \mathrm{H} 2$, $\mathrm{H} 3$ and $\mathrm{H} 4$. The hybrid composites $\mathrm{H} 1$ and $\mathrm{H} 3$ are the laminates with fiber orientation at $0^{\circ}$, whose structure represents a symmetrical arrangement of the layers relative to the medial one. The hybrid composites $\mathrm{H} 2$ and $\mathrm{H} 4$ are the laminates with fiber orientation at various angles, whose structure represents an antisymmetrical balanced arrangement of the layers relative to the medial one. The plies configuration of the fabric reinforced hybrid epoxy composite with $0^{\circ}$ fiber orientation $\mathrm{H} 1$ is $\left[\mathrm{C}_{0} / \mathrm{A}_{0} / \mathrm{A}_{0} / 1 \mathrm{G}_{0} / 2 \mathrm{G}_{0} /\right.$ $\left.1 \mathrm{G}_{0} / \mathrm{C}_{0} / \mathrm{A}_{0} / \mathrm{M}_{90} / \mathrm{A}_{0} / \mathrm{C}_{0} / 1 \mathrm{G}_{0} / 2 \mathrm{G}_{0} / 1 \mathrm{G}_{0} / \mathrm{A}_{0} / \mathrm{A}_{0} / \mathrm{C}_{0}\right]$. The plies configuration of composite material $\mathrm{H} 2$ is similar to that of composite material $\mathrm{H} 1$, but with fiber orientation at various angles, as $\left[\mathrm{C}_{0} / \mathrm{A}_{-15} / \mathrm{A}_{15} / 1 \mathrm{G}_{\text {- }}\right.$ ${ }_{30} / 2 \mathrm{G}_{0} / 1 \mathrm{G}_{30} / \mathrm{C}_{45} / \mathrm{A}_{0} / \mathrm{M}_{90} / \mathrm{A}_{0} / \mathrm{C}_{45} / 1 \mathrm{G}_{45} / 2 \mathrm{G}_{0} / 1 \mathrm{G}_{45} / \mathrm{A}_{15} / \mathrm{A}$. $\left.{ }_{15} / \mathrm{C}_{0}\right]$. The layers configuration of the hybrid composite $\mathrm{H} 3$

$\left[\mathrm{C}_{0} / \mathrm{C}_{0} / \mathrm{A}_{0} / 1 \mathrm{G}_{0} / 2 \mathrm{G}_{0} / 1 \mathrm{G}_{0} / \mathrm{A}_{0} / \mathrm{C}_{0} / \mathrm{M}_{90} / \mathrm{C}_{0} / \mathrm{A}_{0} / 1 \mathrm{G}_{0} / 2 \mathrm{G}_{0} / 1 \mathrm{G}\right.$ $\left.{ }_{0} / \mathrm{A}_{0} / \mathrm{C}_{0} / \mathrm{C}_{0}\right]$. As in case of hybrid epoxy composite $\mathrm{H} 1$ 
and $\mathrm{H} 2$, the plies configuration of composite material $\mathrm{H} 4$ is similar to that of composite material $\mathrm{H} 3$, but with fiber orientation at various angles, as $\left[\mathrm{C}_{0} / \mathrm{C}\right.$. ${ }_{15} / \mathrm{A}_{15} / 1 \mathrm{G}_{-30} / 2 \mathrm{G}_{0} / 1 \mathrm{G}_{30} / \mathrm{A}_{45} / \mathrm{C}_{0} / \mathrm{M}_{90} / \mathrm{C}_{0} / \mathrm{A}_{45} / 1 \mathrm{G}_{45} / 2 \mathrm{G}_{0} /$ $\left.1 \mathrm{G}_{45} / \mathrm{A}_{15} / \mathrm{C}_{-15} / \mathrm{C}_{0}\right]$.

The epoxy matrix of the fabric reinforced hybrid plates is a stratified filled matrix made of three types of fillers mixtures, such as: MF1 - polymeric mixture with $10 \mathrm{wt} \%$ of potatoes starch and $10 \mathrm{wt} \%$ of carbon black, which was used for layers 01 to 03 and 15 to17; MF2 - polymeric mixture with 5 wt. $\%$ of potatoes starch, 5 wt. $\%$ of aramid powder, 5 wt. $\%$ of glass whiskers and 5 wt.\% of carbon whiskers, which was used for layers 04 to 06 and 12 to 14; MF3 polymeric mixture with $10 \mathrm{wt}$. $\%$ of aramid powder and $10 \mathrm{wt} \%$ of barium ferrite, used for layers 07 to 11.

The hybrid epoxy composites reinforced with fabrics and with stratified filled matrix were formed by wet lay-up method. By this method each layer of the plates was placed into a glass mould and imbued with the prepolymeric and fillers mixtures. After complete polymerization the plates were cured thermally according to technical specifications and the water jet machine was used to extract the specimens for specific heat measurements.

\subsection{Experimental method}

The specific heat of these hybrid epoxy composites reinforced with fabrics and stratified filled matrix was measured using Differential Scanning Calorimetry (DSC 1) instrument from Mettler Toledo and data acquisition and evaluation software STARe. For these thermal tests were used specimens with diameter of $3 \mathrm{~mm}$. The specific heat of the hybrid composite materials was investigated by heating in the temperature range of $30-330^{\circ} \mathrm{C}$ and by cooling in the temperature range of $330-30{ }^{\circ} \mathrm{C}$ with $20^{\circ} \mathrm{C} / \mathrm{min}$. In order to study the influence of filled mixtures on specific heat of the formed composites, it was measured the specific heat for unfilled epoxy matrix (ME) and for each filled epoxy matrices (MF1, MF2 and MF3) in the similar temperature ranges. As example, the averaged values of the heat flow and specific heat measured in the temperature range of 30-330 ${ }^{\circ} \mathrm{C}$ for hybrid composite material $\mathrm{H} 1$ are presented in Figure 1.

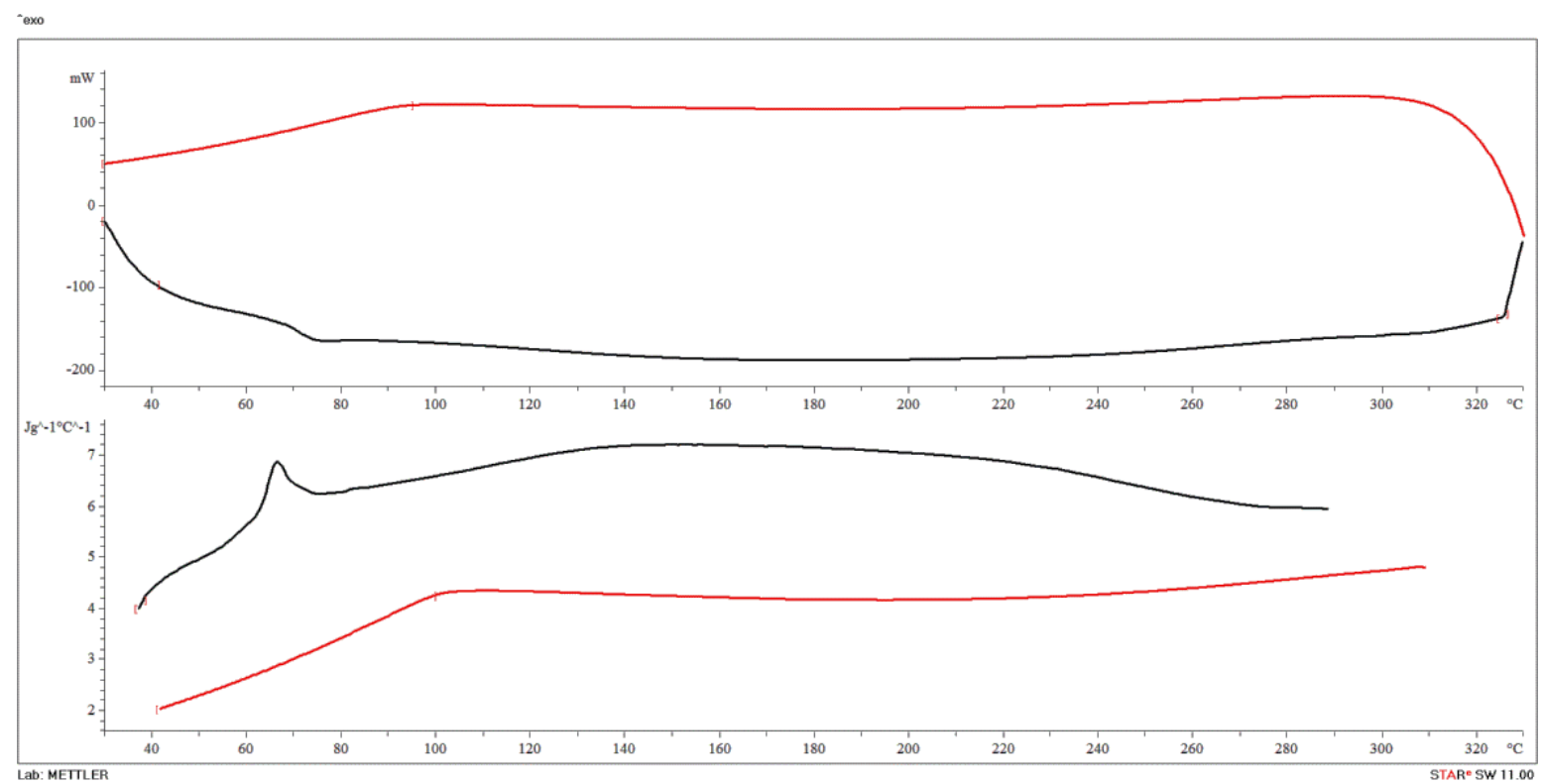

Fig. 1. Heat flow vs temperature (above) and specific heat vs temperature (below) curves for hybrid composite $\mathrm{HI}$

\section{Results and discussion}

The investigation of specific heat was performed on the limits of the linear portions of both specific heat vs temperature curves (heating and cooling curves showed in Fig. 1). So, the specific heat of epoxy matrices and hybrid epoxy composites reinforced with fabrics and with stratified filled matrix was analysed in the heating and cooling temperature ranges of $50-60{ }^{\circ} \mathrm{C}, 80-100{ }^{\circ} \mathrm{C}, 100-150$ ${ }^{\circ} \mathrm{C}, 160-200{ }^{\circ} \mathrm{C}$ and $200-240{ }^{\circ} \mathrm{C}$. The average values of the specific heat of unfilled epoxy matrix (ME) and filled epoxy matrices (MF1, MF2 and MF3) determined in the heating temperature ranges are presented in Fig. 2 and those determined in the cooling temperature ranges are showed in Fig. 3. It 
can be observed that the values of specific heat in the cooling temperature ranges are, generally, lower than those in the heating temperature ranges, excepting specific heat evaluated in the temperature range of $50-60{ }^{\circ} \mathrm{C}$. The addition of $20 \mathrm{wt} \%$ of potatoes starch and carbon black into epoxy matrix led to a decreasing of specific heat values in all temperature ranges. Regarding the specific heat of the filled epoxy matrices measured in the heating temperatures ranges (Fig. 2), it can be seen that the epoxy matrix filled with 20 wt. $\%$ of aramid powder and barium ferrite showed in all temperatures ranges almost the same values with those obtained in case of epoxy matrix filled with 20 wt.\% of potatoes starch and carbon black. The amount of $20 \mathrm{wt} \%$ of potatoes starch, aramid powder and glass and carbon whiskers showed no influence on the specific heat values of epoxy matrix in the temperature ranges of $50-60{ }^{\circ} \mathrm{C}$, $80-100{ }^{\circ} \mathrm{C}$ and $100-150{ }^{\circ} \mathrm{C}$, but it led to an increasing of the values in the temperature ranges of $160-200^{\circ} \mathrm{C}$ and $200-240{ }^{\circ} \mathrm{C}$.

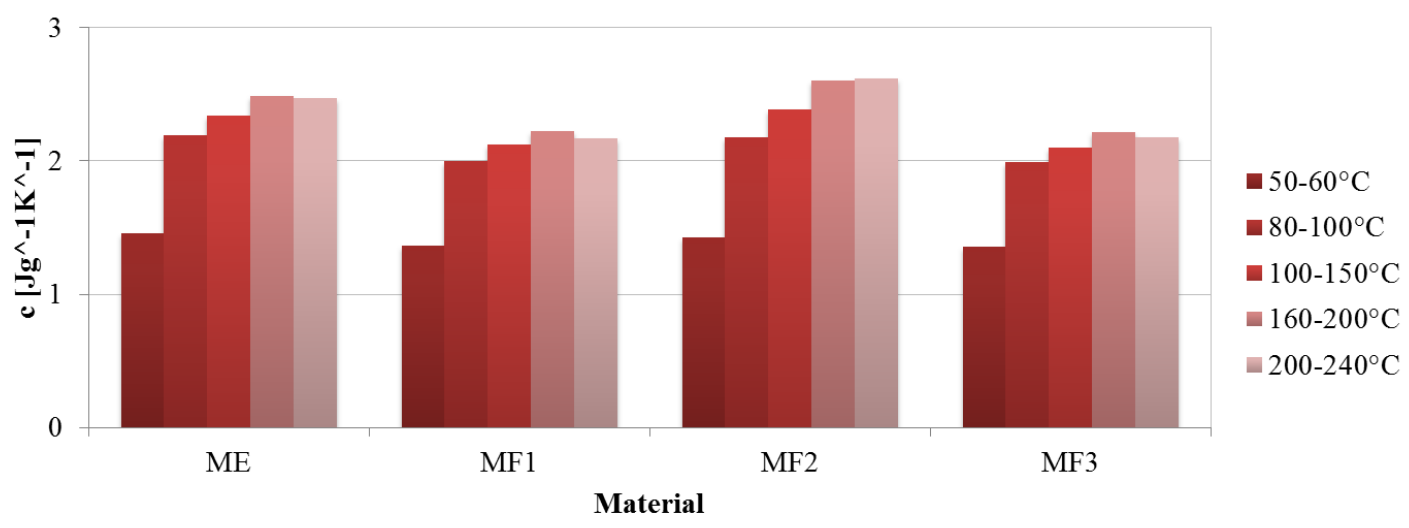

Fig. 2. Specific heat of epoxy matrices measured in the heating temperature ranges

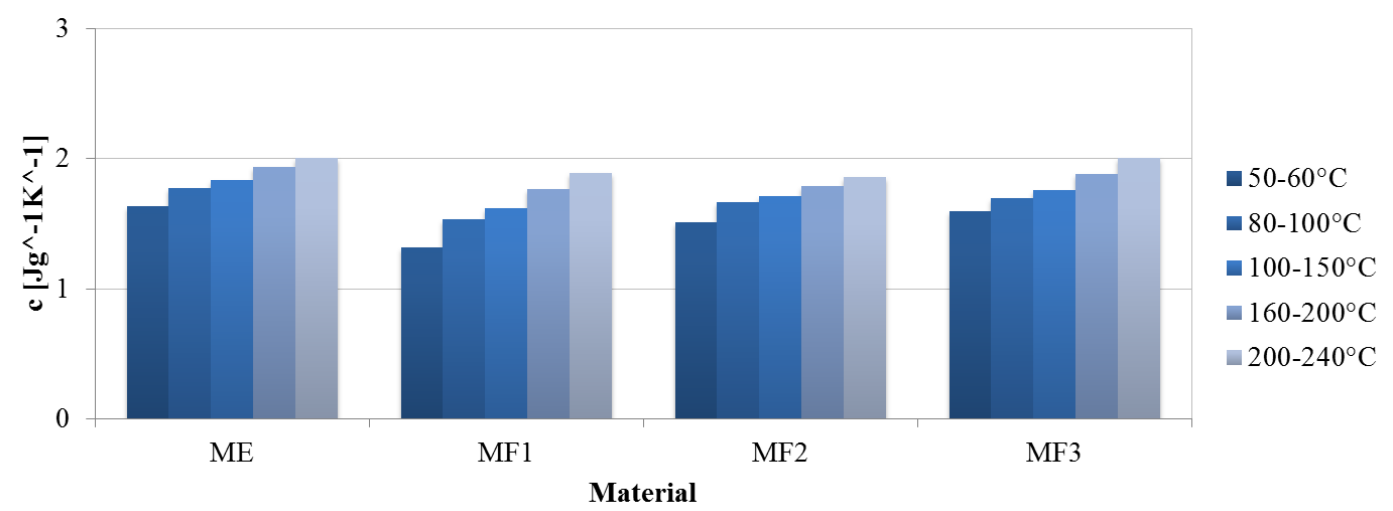

Fig. 3. Specific heat of epoxy matrices measured in the cooling temperature ranges

In the cooling temperature ranges (Fig. 3), it can be seen that the specific heat of filled epoxy matrices exhibited lower value in comparison with those of unfilled epoxy matrix. The epoxy matrix filled with 20 wt.\% of aramid powder and barium ferrite (MF3) showed in all temperatures ranges the values close to those presented by unfilled epoxy matrix (ME). The lowest values of specific heat were obtained in case of epoxy matrix filled with $20 \mathrm{wt}$. $\%$ of potatoes starch and carbon black (MF1) in the temperature ranges of $50-60{ }^{\circ} \mathrm{C}, 80-100{ }^{\circ} \mathrm{C}, 100-150{ }^{\circ} \mathrm{C}$ and $160-200{ }^{\circ} \mathrm{C}$, but the lowest values in the temperature range of 200-240 ${ }^{\circ} \mathrm{C}$ were determined in case of epoxy matrix filled with 20 wt. $\%$ of potatoes starch, aramid powder and glass and carbon whiskers (MF2).

In Figures 4 and 5 are plotted the average values of specific heat measured for hybrid epoxy composites reinforced with fabrics and stratified filled matrix in the same temperature ranges as in case of filled matrices. It can be observed that the hybrid epoxy laminates presented, also, higher values of specific heat determined in the heating temperature ranges compared to those determined in the cooling temperature ranges. Thus, the hybrid epoxy laminates need a larger amount of heat to increase their temperature with a unit, while for their temperature 
reduction with a unit it is necessary a lower amount of heat to release. Regarding the number of aramid and carbon plies in structure of hybrid epoxy composite materials, it can be seen in Fig. 4 that the hybrid epoxy composites with more aramid layers (H1 and H2) showed higher values of the specific heat in all heating temperature ranges as compared to those obtained in case of hybrid epoxy composites with more carbon layers (H3 and $\mathrm{H} 4)$. The fiber orientation at various angles $\left( \pm 15^{\circ}, \pm 30^{\circ}\right.$ and $\left.\pm 45^{\circ}\right)$ led to a significant increase of specific heat values in all heating temperature ranges.

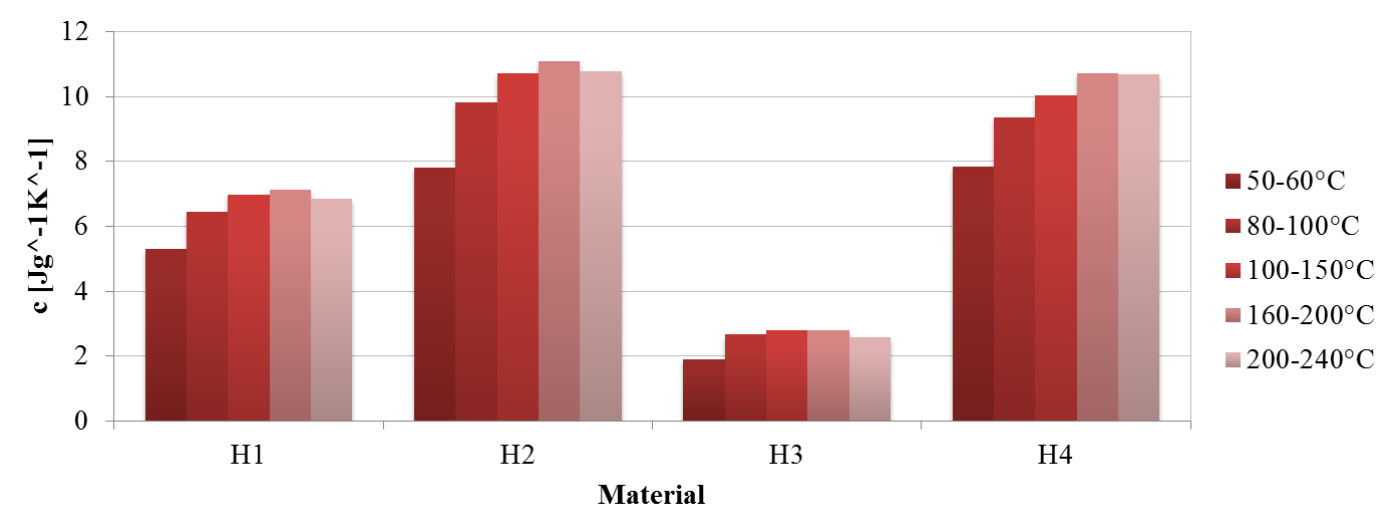

Fig. 4. Specific heat of hybrid composite materials measured in the heating temperature ranges

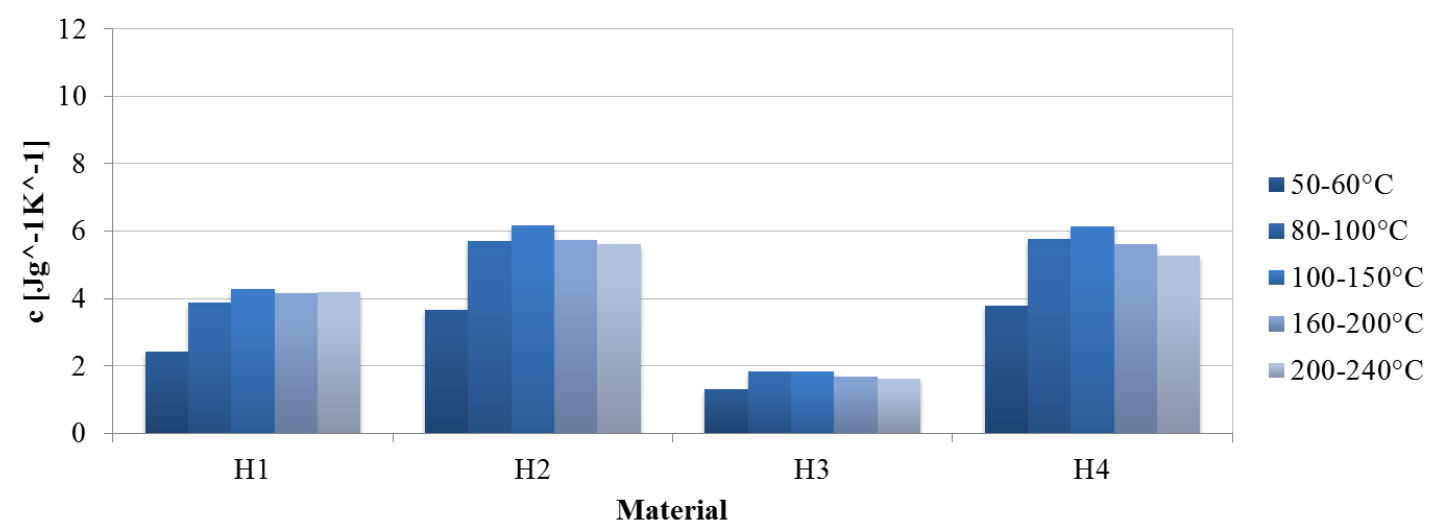

Fig. 5. Specific heat of hybrid composite materials measured in the cooling temperature ranges

The values of specific heat measured in the cooling temperature ranges of $50-60{ }^{\circ} \mathrm{C}, 80-100{ }^{\circ} \mathrm{C}$, $100-150{ }^{\circ} \mathrm{C}, 160-200{ }^{\circ} \mathrm{C}$ and $200-240{ }^{\circ} \mathrm{C}$ for hybrid epoxy composites reinforced with fabrics and stratified filled matrix (Fig. 5) showed that the fiber orientation at various angles led to a significant increase, as in case of those measured in the heating temperature ranges. If we compare the composites with fiber orientation at $0^{\circ}$, it can be seen that the ones with more aramid plies presented much higher values of specific heat as compared to the ones with more carbon plies.

But if we compare the composites with fiber orientation at various angles, it can be observed that the ones with more carbon plies showed higher value of specific heat in the temperature ranges of $50-60{ }^{\circ} \mathrm{C}$ and $80-100{ }^{\circ} \mathrm{C}$ as compared to the ones with more aramid plies. But in the temperature ranges of 100 $150{ }^{\circ} \mathrm{C}, 160-200{ }^{\circ} \mathrm{C}$ and $200-240{ }^{\circ} \mathrm{C}$ the highest values of specific heat were obtained in case of hybrid composite material with more aramid plies.

\section{Conclusions}

The influence of filler mixture types, number of carbon and aramid layers and fiber orientation at various angles $\left( \pm 15^{\circ}, \pm 30^{\circ}\right.$ and $\left.\pm 45^{\circ}\right)$ on specific heat of hybrid epoxy composites reinforced with fabrics and with filled stratified matrix measured in the in the heating and cooling temperature ranges of $50-60{ }^{\circ} \mathrm{C}$, 80-100 ${ }^{\circ} \mathrm{C}, 100-150{ }^{\circ} \mathrm{C}, 160-200{ }^{\circ} \mathrm{C}$ and $200-240{ }^{\circ} \mathrm{C}$ was investigated. It can be made the following conclusions by analysis of obtained and plotted above experimental data: 
- The investigation of the influence of filler mixtures on specific heat of epoxy matrix showed that the amount of $20 \mathrm{wt} . \%$ of potatoes starch, aramid powder and glass and carbon whiskers had no influence in the heating temperature ranges of 50-60 ${ }^{\circ} \mathrm{C}, 80-100{ }^{\circ} \mathrm{C}$ and $100-150{ }^{\circ} \mathrm{C}$, but it led to an increase of the values in the temperature ranges of $160-200{ }^{\circ} \mathrm{C}$ and $200-240{ }^{\circ} \mathrm{C}$. The epoxy matrix filled with 20 wt.\% of aramid powder and barium ferrite and that filled with 20 wt.\% of potatoes starch and carbon black showed in all heating temperatures ranges almost the same values, but lower as compared to the ones of unfilled epoxy matrix.

- In the cooling temperature ranges of $50-60^{\circ} \mathrm{C}$, 80-100 ${ }^{\circ} \mathrm{C}, 100-150{ }^{\circ} \mathrm{C}$ and $160-200{ }^{\circ} \mathrm{C}$ the lowest values of specific heat were obtained in case of epoxy matrix filled with 20 wt.\% of potatoes starch and carbon black, but in the temperature range of 200-240 ${ }^{\circ} \mathrm{C}$ the lowest values was determined in case of epoxy matrix filled with $20 \mathrm{wt} . \%$ of potatoes starch, aramid powder and glass and carbon whiskers.

- The hybrid epoxy composites with more aramid layers exhibited much higher values of the specific heat in all heating and cooling temperature ranges as compared to the ones determined in case of hybrid epoxy composites with more carbon layers.

- The fiber orientation at various angles led to a significant increase of specific heat values in all heating temperature ranges, especially, for hybrid epoxy composites with more carbon layers. The composite materials with more carbon plies exhibited the highest value of specific heat in the cooling temperature ranges of $50-60{ }^{\circ} \mathrm{C}$ and $80-100{ }^{\circ} \mathrm{C}$. But the composite material with more aramid layers presented the highest values in the temperature ranges of $100-150{ }^{\circ} \mathrm{C}, 160-200{ }^{\circ} \mathrm{C}$ and $200-240{ }^{\circ} \mathrm{C}$.

\section{Acknowledgements}

This work has been funded by the European Social Fund through the Sectoral Operational Programme Human Capital 2014-2020, through the Financial Agreement with the title „Burse pentru educaţia antreprenorială în rândul doctoranzilor şi cercetătorilor postdoctorat (Be Antreprenor!)" (in English: "Scholarships for entrepreneurial education among doctoral students and postdoctoral researchers (Be Entrepreneur!)", Contract no. 51680/09.07.2019 SMIS code: 124539.

\section{References}

[1]. Vidal P., Gallimard L., Ranc I., Polit O., Thermal and thermo-mechanical solution of laminated composite beam based on a variables separation for arbitrary volume heat source locations, Applied Mathematical Modelling, 46, p. 98-115, https://doi.org/10.1016/j.apm.2017.01.064, 2017.
[2]. Saba N., Jawaid M., A review on thermomechanical properties of polymers and fibers reinforced polymer composites, Journal of Industrial and Engineering Chemistry, 67, p. 1-11, https://doi.org/10.1016/j.jiec.2018.06.018, 2018.

[3]. Melvin A. D., Lucia A. C., Solomos G. P., The thermal response to deformation to fracture of a carbon/epoxy composite laminate, Composites Science and Technology, 46, p. 345-351. https://doi.org/10.1016/0266-3538(93)90180-O, 1993.

[4]. Karnati S. R., Agbo P., Zhang L., Applications of silica nanoparticles in glass/carbon fiber-reinforced epoxy nanocomposite, Composites Communications, 17, p. 32-41, https://doi.org/10.1016/j.coco.2019.11.003, 2020.

[5]. Praveen R. S., Jacob S., Murthy C. R. L., Balachandran P., Rao Y. V. K. S., Hybridization of carbon-glass epoxy composites: An approach to achieve low coefficient of thermal expansion at cryogenic temperatures, Cryogenics, 51, p. 95-104. https://doi.org/10.1016/j.cryogenics.2010.12.003, 2011.

[6]. Birsan I. G., Roman I., Bria V., Ungureanu V., Circiumaru A., Starch-Epoxy Composites, Annals of DAAAM for 2011 \& Proceedings of the $22^{\text {nd }}$ International DAAAM Symposium, $22 \mathrm{p}$. 285-286, 2011.

[7]. Abdel-Aal N., El-Tantawy F., Al-Hajry A., Bououdina M., Epoxy resin/plasticized carbon black composites. Part I. Electrical and thermal properties and their applications, Polymer Composites, 29, p. 511-517, https://doi.org/10.1002/pc.20401, 2008.

[8]. Bera T., Acharya S. K., Mishra P., Synthesis, mechanical and thermal properties of carbon black/epoxy composites, International Journal of Engineering, Science and Technology, 10, p. 12-20, https://doi.org/10.4314/ijest.v10i4.2, 2018.

[9]. Muntenita C., Ungureanu C., Bria V., Graur I., Specific heat of nano-ferrites modified composites, MATEC Web of Conferences, 112, 04016, 2017.

[10]. Birsan I. G., Bria V., Circiumaru A., Roman I., Characterization of particulate epoxy composites, The Annals of University "Dunărea de Jos" of Galati, Fascicle VIII, XV, p. 83-87, 2009.

[11]. Jarosinski L., Rybak A., Gaska K., Kmita G., Porebska R., Kapusta C., Enhanced thermal conductivity of graphene nanoplatelets epoxy composites, Materials Science-Poland, 35, p. 382-389, https://doi.org/10.1515/msp-2017-0028, 2017.

[12]. Zhu D., Qi Y., Yu W., Chen L., Wang M., Xie H., Enhanced Thermal Conductivity for Graphene Nanoplatelets/Epoxy Resin Composites, Journal of Thermal Science and Engineering Applications, 10, 2018.

[13]. Wang F., Drzal L. T., Qin Y., Huang Z., Mechanical properties and thermal conductivity of graphene nanoplatelet/epoxy composites, Journal of Materials Science, 50, p. 1082-1093, https://doi.org/10.1007/s10853-014-8665-6, 2015.

[14]. Park J. G., Cheng Q., Lu J., Bao J., Li S., Tian Y., Liang Z., Zhang C., Wang B., Thermal conductivity of MWCNT/epoxy composites: The effects of length, alignment and functionalization, Carbon, 50, p. 2083-2090, 2012.

[15]. Yang S. Y., Ma C. C. M., Teng C. C., Huang Y. W., Liao S. H., Huang Y. L., Tien H. W., Lee T. M., Chiou K. C., Effect of functionalized carbon nanotubes on the thermal conductivity of epoxy composites, Carbon, 48, p. 592-603. https://doi.org/10.1016/j.carbon.2009.08.047, 2010.

[16]. Caradonna A., Badini C., Padovano E., Pietroluongo M., Electrical and Thermal Conductivity of Epoxy-Carbon Filler Composites Processed by Calendaring, Materials, 12, 1522, https://doi.org/10.3390/ma12091522, 2019.

[17]. Majeed N. S., Salih S. M., Abdulmajeed B. A., Effect of nanoparticles on thermal conductivity of epoxy resin system, IOP Conference Series: Materials Science and Engineering, 518, 062006, https://doi.org/10.1088/1757-899X/518/6/062006, 2019.

[18]. Li X., Park W., Chen Y. P., Ruan X., Effect of Particle Size and Aggregation on Thermal Conductivity of Metal-Polymer Nanocomposite, Journal of Heat Transfer, 139, https://doi.org/10.1115/1.4034757, 2017. 


\section{THE ANNALS OF “DUNAREA DE JOS” UNIVERSITY OF GALATI \\ FASCICLE IX. METALLURGY AND MATERIALS SCIENCE \\ No. 2 - 2019, ISSN 2668-4748; e-ISSN 2668-4756 \\ Article DOI: https://doi.org/10.35219/mms.2019.2.06}

[19]. Thipperudrappa S., Ullal Kini A., Hiremath A., Influence of zinc oxide nanoparticles on the mechanical and thermal responses of glass fiber-reinforced epoxy nanocomposites, Polymer Composites, https://doi.org/10.1002/pc.25357, 2019.

[20]. Kandare E., Khatibi A. A., Yoo S., Wang R., Ma J., Olivier P., Gleizes N., Wang C. H., Improving the throughthickness thermal and electrical conductivity of carbon fibrelepoxy laminates by exploiting synergy between graphene and silver nanoinclusions, Composites Part A: Applied Science and Manufacturing, 69, p. 72-82, 2015.

[21]. Bunea M., Cîrciumaru A., Buciumeanu M., Bîrsan I. G. Silva F. S., Low velocity impact response of fabric reinforced hybrid composites with stratified filled epoxy matrix, Composites Science and Technology, 169, p. 242-248. https://doi.org/10.1016/j.compscitech.2018.11.024, 2019.

[22]. Bunea M., Bosoanca R., Eni C., Cristache N., Stefanescu V., The impact characteristics of fabric reinforced hybrid composites, Materiale Plastice, 54, p. 286-290, 2017.

[23]. Bunea M., Bosoanca I., Bosoanca R., Bodor M., Circiumaru A., Bending and Compressive Properties of Fabric Reinforced Composites, Materiale Plastice, 52, p. 368-372, 2015.

[24]. Bria V., Cîrciumaru A., Bîrsan I. G., Some Properties of Starch/Epoxy Composites, Materiale Plastice, 48, p. 189-194, 2011. 